\title{
El procedimiento de reconocimiento extrajudicial de créditos. Nulidad de las actuaciones administrativas y responsabilidad
}

\author{
Carmen Carretero Espinosa de los Monteros \\ Letrada jefe de la Cámara de Cuentas de Andalucía \\ Letrada de la Junta de Andalucía
}

\begin{abstract}
SUMARIO: I. INTRODUCGIÓN: SOBRE LA PLANIFICACIÓN Y LAS NEGESIDADES PÚBLICAS. II. SOBRE LAS OBLIGACIONES ASUMIDAS AL MARGEN DE LA DEBIDA GONSIGNAGIÓN PRESUPUESTARIA. III. SOBRE LA APLICACIÓN DEL PROCEDIMIENTO DE RECONOGIMIENTO EXTRAJUDICIAL DE GRÉDITOS. IV. RESPONSABILIDAD V. GONCLUSIONES.
\end{abstract}

\section{RESUMEN}

Ante la existencia de pagos sin consignación presupuestaria previa, las leyes hacendísticas imponen la nulidad de pleno derecho de los actos y disposiciones administrativas. No obstante, la invalidez de los actos administrativos no exime a la Administración de la obligación de abono de las prestaciones realizadas por un tercero a su favor, en virtud del principio general del derecho de evitación del enriquecimiento injusto.

El procedimiento de reconocimiento extrajudicial de créditos se configura como un procedimiento excepcional para la solución del problema.

Asimismo ante la existencia de pagos sin consignación presupuestaria, nuestro Ordenamiento jurídico prevé la responsabilidad contable y un régimen sancionador específico.

\section{PALABRAS GLAVE}

Gasto público. Consignación presupuestaria. Procedimiento de reconocimiento extrajudicial de créditos. Nulidad. Convalidación. Responsabilidad. 


\section{ABSTRACT}

Given the existence of payments without budgetary provision, the laws impose the nullity of administrative actions. However, this invalidity of administrative actions does not relieve the Administration of the obligation of payment of services provided by third party on their behalf, under the general principle of law, the theory of unjust enrichment.

Extrajudicial recognition of credit is configured as a procedure outstanding, conducive to solve the problem.

Also before the existence of payments without budgetary provision, our law provides accounting responsibility and specific sanctions.

\section{KEY WORDS}

Public spending. Budgetary provision. Procedure of extrajudicial recognition of credits. Nullity. Validation. Responsibility.

\section{INTRODUCGIÓN: SOBRE LA PLANIFICACION Y LAS NE- CESIDADES PÚBLICAS}

Como es sabido, los Estados modernos planifican la cobertura de las necesidades generales a través de los presupuestos públicos, los cuales adoptan la forma de Ley. Se trata en cualquier caso de una ley autorizante, en el sentido de que el Poder Legislativo autoriza a la Administración a la realización de los gastos en la cuantía y con el destino permitidos por el Parlamento. De este modo, si el Presupuesto con relación a los ingresos tiene una naturaleza de mera previsión, con relación a los gastos es una auténtica norma jurídica vinculante que fija el importe, destino y las reglas que ha de observar la Administración Pública en el ejercicio de su poder de ejecución, durante un determinado ejercicio económico, erigiéndose en «(...) la expresión cifrada, conjunta y sistemática de los derechos y obligaciones a liquidar durante el ejercicio por cada uno de los órganos y entidades que forman parte del sector público estatal» siguiendo lo dicho en el art. 32 de la Ley 47/2003, de 26 de noviembre General Presupuestaria (en adelante LGP) ${ }^{1}$.

${ }^{1}$ En idéntico sentido, artículo 31 del TRLGHPJA siguiendo lo dispuesto en el art. 190. 2 del Estatuto de Autonomía para Andalucía lo define como «(...) la expresión cifrada, conjunta y sistemática de las obligaciones que, como máximo, pueden reconocer la Junta de Andalucía, sus agencias administrativas y de régimen especial y sus instituciones, y de los derechos que prevean liquidar durante el correspondiente ejercicio, así como las estimaciones de gastos e ingresos a realizar por las agencias públicas empresariales, por las sociedades mercantiles del sector público andaluz, por los consorcios, fundaciones y las demás entidades previstas en el artículo 5.1 de la presente ley, y por la dotación para operaciones finan- 
Pero esta función autorizatoria de las Leyes de Presupuestos no puede entenderse al margen de la propia configuración del Estado y del Ordenamiento jurídico en su conjunto, impregnado por los principios generales del Derecho. El artículo 1 de la Constitución nos dice que España se constituye en un Estado social y de derecho, y ello debe determinar que el Estado, -y en concreto el Poder Ejecutivo al que le corresponde la satisfacción de las necesidades sociales-, no se desentienda bajo una interpretación aislada de las normas, de la necesaria satisfacción de las necesidades colectivas más apremiantes, de los imprevistos surgidos en la fase de ejecución de los Presupuestos que determinen nuevos gastos urgentes e inaplazables. Ello habrá de determinar inevitablemente, la flexibilización del grado de vinculación de la Administración al mandato originario recibido del poder legislativo. Como señalan PITA GRANDAL y FERNÁNDEZ LÓPEZ², «No en vano, cuando el art. 31.2 de la Constitución consagra la máxima de que no sólo la programación sino también la «ejecución» del gasto público deberá responder a los criterios de «eficiencia y economía», implícitamente se le está atribuyendo al órgano gestor del presupuesto la potestad, pero al mismo tiempo el deber, de decidir y articular medidas que, sin apartarse de los cauces de actuación propios del Derecho Público a que está sometida la Administración, ofrezcan soluciones inmediatas y eficientes a las necesidades urgentes surgidas en el curso del ejercicio presupuestario».

Parece así razonable, que el Ordenamiento jurídico haya previsto cauces o instrumentos jurídicos, que desde la vertiente del gasto, permitan afrontar las necesidades inaplazables nacidas durante un determinado ejercicio presupuestario. A estos efectos, el artículo 51 LGP enumera las distintas clases de modificaciones presupuestarias, desarrollando su sentido en los siguientes preceptos. En el mismo orden la sección $2^{\text {a }}$ del Capítulo I y Título VI del Texto refundido de la Ley Reguladora de las Haciendas Locales, aprobado por Real Decreto Legislativo 2/2004, de 5 de marzo (en adelante TRLRHHLL), bajo la rúbrica "De los créditos y sus modificaciones"; Por su parte el Texto Refundido de la Ley General de la Hacienda Pública de la Junta de Andalucía, aprobado por Decreto Legislativo 1/2010, de 2 de marzo, contiene previsiones similares en el capítulo II del Título VI rubricado "Los créditos y sus modificaciones".

cieras de los fondos regulados en el artículo 5.3.». Redacción y definición similar encontramos también en el artículo 162 del Texto refundido de la Ley Reguladora de las Haciendas Locales, aprobado por Real Decreto Legislativo 2/2004, de 5 de marzo (en adelante TRLRHHLL).

${ }^{2}$ PITA GRANDAL, A.M. y FERNANDEZ LÓPEZ, R.I., "El procedimiento de ejecución del gasto público ante situaciones de emergencia". Revista española de derecho financiero, ISSN 0210-8453, N ${ }^{\circ}$ 133, 2007, págs. 101-128. 
Pero al margen de estas operaciones presupuestarias perfectamente formalizadas, existen numerosos supuestos en los que efectivamente se asumen compromisos de gastos no autorizados en las correspondientes Leyes Presupuestarias, ni imputados en el ejercicio correspondiente por alguno de los cauces legalmente establecidos. Nos estamos refiriendo a una serie de supuestos tales como contratos que se ejecutan excediendo del periodo fijado como máximo por la normativa con prórrogas ilegales; modificaciones contractuales al margen de los pliegos; contrataciones verbales; excesos de obra admitidos por la Administración; facturas extraviadas ..., por citar algunos supuestos. Se trata de supuestos que responden en muchos casos -aunque no en todos-, a patologías previas en el cumplimiento de la legislación material. Pero siendo ello cierto, no lo es menos que tratamos de un problema al que el Ordenamiento jurídico debe dar solución, siendo su tratamiento en las correspondientes leyes hacendísticas y presupuestarias, los que nos interesa en el presente estudio.

\section{SOBRE LAS OBLIGACIONES ASUMIDAS AL MARGEN DE LA DEBIDA GONSIGNACIÓN PRESUPUESTARIA}

Todo gasto público tiene dos vertientes bien definidas: una interna y otra externa. Desde el punto de vista interno, el gasto público es la consecuencia de la decisión administrativa de emplear fondos públicos para satisfacer una necesidad pública, decisión que se toma y ejecuta siguiendo el correspondiente procedimiento administrativo. Y desde el punto de vista externo, el gasto público da lugar a vínculos jurídicos con terceros, que son el cauce a través del cual el Estado obtiene los bienes y servicios que precisa para dar satisfacción a las necesidades públicas. Se trata por lo tanto de una doble perspectiva que debe ser estudiada.

\section{Aspecto interno del gasto público}

En el aspecto interno del gasto público, el efecto primordial del presupuesto es autorizar o habilitar a la Administración para acordar y ejecutar las decisiones de gasto. Sin la correspondiente autorización presupuestaria la Administración no puede realizar correctamente el procedimiento de gasto público. A su vez, dicha autorización se condiciona al cumplimiento de una serie de límites. Uno primero cualitativo que se formula a través del principio de especialidad (art. 42 LGP; art. 39 TLGHPJA; art. 172.1 TRLRHHLL); otro cuantitativo que se refleja en los artículos 46 LGP, art. 39.2 TRLGHPJA y 173.5 TRLGHHLL, y por último, un límite temporal cifrado en el principio de anualidad presupuestaria.

Respecto del límite cuantitativo, las tres normas hacendísticas - aun con ligeras variantes-, mantienen el mismo contenido, declarando la nulidad de aquellos actos o 
acuerdos que incumplan la señalada limitación. Así el art. 46 LGP cuando señala que «Los créditos para gastos son limitativos. No podrán adquirirse compromisos de gastos ni adquirirse obligaciones por cuantía superior al importe de los créditos autorizados en los estados de gastos, siendo nulos de pleno derecho los actos administrativos y las disposiciones generales con rango inferior a Ley que incumplan esta limitación, sin perjuicio de las responsabilidades reguladas en el título VII de esta ley». En el mismo sentido, el art. 39.2 del TRLGHPJA y 176.5 del TRLRHHLL.

Estas previsiones generales se completan con la de aquellos casos en los que la legislación específica condiciona expresamente la validez de la actuación administrativa a la existencia de crédito presupuestario, como sucede con el artículo 26.1.k) de la Ley de Contratos del Sector Público en relación con el art. 31 de la misma norma, y en el artículo 36.1 b) de Ley General de Subvenciones.

Vemos así, que las leyes presupuestarias y hacendísticas asocian a la inobservancia de este principio limitativo, la sanción más grave de las que se prevén en el ámbito del derecho administrativo, cual es la de la nulidad radical y absoluta de los actos y disposiciones que la contravengan. Y es que, si como antes hemos señalado, la Ley de Presupuestos tiene carácter autorizatorio del gasto a la vez que limitativo, es lo cierto que dicha autorización no lo es en abstracto, sino que se erige en un requisito conformador de la competencia y del procedimiento administrativo. En opinión de FERREIRO LAPATZA ${ }^{3}$, siguiendo a RODRÍGUEZ BEREIJO, la Ley Presupuestaria tiene el efecto jurídico de una atribución de competencia, de tal manera que si no existe crédito adecuado y suficiente, el órgano administrativo no puede prestar válidamente su consentimiento, pues la Ley en estos casos «tiene el efecto de una atribución de competencia», por eso, la sanción en estos casos, es la nulidad de pleno derecho del acto, acuerdo o disposición normativa que infrinja el señalado límite, por cuanto cada órgano, tiene una competencia propia enmarcada cualitativamente, pero también cuantitativamente por mor precisamente de la norma presupuestaria.

La Jurisprudencia por su parte considera que tal falta de consignación presupuestaria constituye una causa de nulidad pero por falta de procedimiento administrativo. Valga a estos efectos, la cita de las SSTS de 15 diciembre 1982 (RJ 7974), de 8 de octubre de 1986 (RJ 7650) o de las sentencias del Tribunal Superior de Justicia de Andalucía de 3 de Febrero de 2000 (RJ 2295) y de Cantabria de 2-2-2004, (RJ

${ }^{3}$ FERREIRO LAPATZA, J.J.: Curso de Derecho Financiero español. Marcial Pons. 2006. 
71245). Considera además - y con razón-, que tratándose de contratos inexistentes no es posible su convalidación (STS de 21 de marzo de 1991 (RJ 2013), citada también en la sentencia del TSJ de Cantabria de 9 de enero de 2004). Ocurre sin embargo, que esta aparente claridad de la cuestión, no es tal cuando se tiene en cuenta la otra vertiente del gasto, cual es la externa como veremos a continuación.

\section{Aspecto externo del gasto público}

En el aspecto externo del gasto público, hay que referirse a los efectos del presupuesto sobre las obligaciones económicas contraídas con terceros, y a la exigibilidad del pago.

En este punto resulta esencial remitirse a lo dispuesto en los artículos 20 y 21 de la LGP que regulan el origen de las obligaciones económicas del Estado, siendo idéntico el sentido del art. 26. 1 y 2 del TRLGHPJA, y art. 173.1 TRLGHHLL (a salvo el último supuesto). El art. 20 LGP sienta que «Las obligaciones de la Hacienda Pública estatal nacen de la Ley, de los negocios jurídicos y de los actos o hechos que, según Derecho, las generen», y por su parte, el art. 21.1 de la misma norma añade que «Las obligaciones de la Hacienda Pública estatal sólo son exigibles cuando resulten de la ejecución de los presupuestos, de conformidad con lo dispuesto en esta Ley, de sentencia judicial firme o de operaciones no presupuestarias legalmente autorizadas».

Siguiendo a MENÉNDEZ MORENO ${ }^{4}$, para la interpretación de ambos preceptos la doctrina financiera defiende dos tesis diferenciadas. Un sector doctrinal, partiendo de la distinción entre obligaciones legales (nacidas ex lege) y obligaciones voluntarias (nacidas de actos o contratos administrativos) -dada la similitud de dicho precepto con el art. 1089 del Código Civil-, llega a la conclusión integradora de que las obligaciones legales nacen siempre válidamente exista o no crédito presupuestario para su cobertura y, en su caso, la carencia de éste sólo afectaría a la exigibilidad de la obligación contraída, lo que tiene su lógica habida cuenta de que la asunción de la obligación también se produce en una ley, pudiendo considerarse que por ello habilita el gasto. Por el contrario, respecto a las obligaciones voluntarias, la inexistencia de crédito presupuestario afectaría directamente a la validez de las mismas.

Otro sector de la doctrina no distingue entre diferentes tipos de obligaciones por razón de la fuente de su nacimiento, y considera que la no existencia de crédito

${ }^{4}$ MENENDEZ MORENO, A. "Efectos jurídicos de las Leyes de Presupuestos Generales del Estado". Lex Nova Thomson Reuters. 2013. 
presupuestario para la cobertura de la obligación no puede afectar a su validez, pues ésta dependerá del título que la haya originado. Lo que existirá, será un problema de exigibilidad, pero no de validez del título jurídico.

Esta interpretación, -que es más favorable a los derechos de los acreedores-, fue refrendada por el Tribunal Constitucional, al reconocer la autonomía de la fuente de las obligaciones de la Hacienda Pública respecto al crédito presupuestario, afirmando que «(...) los créditos consignados en los estados de gastos de los Presupuestos Generales no son fuente alguna de obligaciones; sólo constituyen autorizaciones legislativas para que dentro de unos determinados limites la Administración del Estado pueda disponer de los fondos públicos necesarios para hacer frente a sus obligaciones. La fuente de éstas debe buscarse fuera de dichas consignaciones presupuestarias, ya sea en la Ley, ya en los negocios jurídicos o en los actos o hechos que, según Derecho, las generen...» (SSTC 63/1986, de 21 de marzo; 146/1986, de 26 de noviembre; y 294/1994, de 7 de noviembre).

Este es también, el camino que ha seguido la Jurisprudencia, que aun partiendo de que estamos ante un contrato inexistente por falta de consignación presupuestaria sitúa la solución del problema en la aplicación de la doctrina del enriquecimiento injusto que "viene a corregir situaciones de total desequilibrio, en relaciones que, carentes de ropaje jurídico, materialmente han existido produciendo beneficios concretos en una de las partes, a costa de la otra. Con ello se originan unos efectos sin causa-enriquecimiento y empobrecimiento- al no venir respaldados por las formas exigidas en el régimen administrativo. Mas estos efectos, sin causa, por la forma, se convierten en determinantes de la causa que los corrige y repara" (STS 348/2015, de 23 de marzo, asumiendo otra anterior de unificación de doctrina de 28 de abril de 2008). Y es que como puso de manifiesto la también STS de 8 de octubre de 1986 (R.J. 1986/7650), no seguir esta vía de contemplación de la realidad no es admisible, por cuanto en los supuestos en los que se declare que «tal cantidad no sea exigible por falta de consignación presupuestaria para poder ser atendido su pago pues este dato, aun de ser cierto, carece de trascendencia en orden a los efectos pretendidos en esta fase del proceso pues en caso contrario la efectividad de las obligaciones municipales quedaria al arbitrio de la correspondiente Corporación lo que no es permisible a tenor de lo establecido en el artículo 1256 del Código Civil, y en las Sentencias del Tribunal Supremo de 9-3-1907 y 1-7-1947 ( Rf 19471953)»5

\footnotetext{
${ }^{5}$ Resulta también interesante conocer en el ámbito de la Jurisdicción social, los pronunciamientos contenidos en las sentencias de 17 de febrero y 30 de septiembre de 2010, de la Sala de lo Social del Tribunal Superior de Justicia de Castilla-León. En estos supuestos, en que se reclamaban diferencias salariales por horas extraordinarias realizadas cuyo pago se negó posteriormente por la existencia de limitaciones presupuestarias, la Sala primero niega que la consecuencia de tal actuación -que en consecuencia no contaba con consignación presupuestaria- fuera su nulidad por aplicación del art. 46 LGP, al no encon-
} 
El problema, como muy bien señaló el Tribunal Constitucional en su STC 294/1994 ya citada, es que para poder comprender esta doble realidad interna y externa, se hace preciso tener en cuenta que existe un peculiar entrecruzamiento de las normas que disciplinan la cuestión. Dada su claridad, -que nos exime de mayores comentarios-, transcribimos las consideraciones vertidas en la sentencia:

"Para una cabal comprensión de esta cuestión en el caso que aqui se trata es preciso arrancar del peculiar entrecruzamiento entre la legalidad administrativa, entendida como sometimiento pleno de la actuación administrativa a la Ley y al Derecho (art. 103.1 CE), $\boldsymbol{y}$ la legalidad presupuestaria en el régimen jurídico de las obligaciones pecuniarias del Estado, en particular de las obligaciones legales que son las que aqui nos importan cuyas vicisitudes aparecen condicionadas en su exigibilidad y momento del pago a la existencia del correspondiente crédito presupuestario consignado en los Presupuestos Generales del Estado.

Las obligaciones económicas del Estado válidamente nacidas de la Ley, de los negocios jurídicos y de los actos o hechos que, según derecho, las generen, no podrán ser cumplidas si no existe crédito presupuestario suficiente para hacerles frente [arts. 42 y 43.1 de la Ley General Presupuestaria ( RCL $1988 \backslash 1966$ y 2287)], siendo nulos los actos de ejecución presupuestaria o de disposición del gasto que incumplan esta prohibición (art. 60 LGP).

Este entrecruzamiento entre el principio de legalidad administrativa y el de legalidad presupuestaria, tiene su raíz en la separación o desconexión entre la fuente de las obligaciones del Estado o título jurídico del cual pueden nacer válidamente las obligaciones económicas del Estado y la fuente del gasto público, esto es el procedimiento específico a través del cual la Hacienda cumple sus obligaciones contraídas y se libera de sus deudas mediante el pago. Como se afirmó en las SSTC 63/1986 ( $\underline{R T C}$ 1986\63), fundamento jurídico 6. ${ }^{\circ}$ y 13/1992 ( RTC 1992\13) fundamento jurídico 5. «los créditos consignados en los estados de gastos de los Presupuestos Gen-

\footnotetext{
trarnos ante actos de naturaleza administrativa sino ante actos empresariales de derecho privado laboral. Después afirma que "en el ámbito laboral, la nulidad no impide el pago de los servicios prestados, con independencia de que pueda producir la extinción de futuro de los compromisos laborales adquiridos contra la norma imperativa (artículo 99 del Estatuto de los Trabajadores). Por consiguiente los salarios devengados por razón del trabajo ya prestado habrían de abonarse en todo caso, independientemente de las responsabilidades de toda índole que incumban a los responsables de la gestión del gasto que decidieron la realización por los trabajadores cuando no existía crédito presupuestario consignado para abonar las mismas". Por lo tanto, tampoco en estos casos la exigibilidad de las obligaciones válidamente nacidas al Derecho se hace depender de la existencia de adecuada consignación en los correspondientes Presupuestos, remitiéndose la cuestión a un problema de responsabilidad de los gestores.
} 
erales del Estado no son fuente alguna de obligaciones; sólo constituyen autorizaciones legislativas para que dentro de unos determinados límites la Administración del Estado pueda disponer de los fondos públicos necesarios para hacer frente a sus obligaciones. La fuente de éstas debe buscarse fuera de dichas consignaciones presupuestarias, ya sea en la ley, ya en los negocios jurídicos o en los actos o hechos que según derecho las generen, tal como señala el art. 42 de la LGP». (...)Y claro es que un Estado de Derecho no puede desconocer una situación jurídica perfecta o una obligación legalmente contraída por el mero hecho de que no exista crédito presupuestario [STC 32/1982 ( $\mathrm{RTC} 1982$ 132), fundamento jurídico $\left.3 .^{\circ}\right]$.

Como ha advertido la Sentencia de la Sala Quinta del Tribunal Supremo, de 6 de marzo de 1978 ( R7 1978 1752), a propósito, precisamente de un supuesto de inactividad administrativa que deja sin cumplimiento un mandato legal de equiparación retributiva entre el Profesorado «sin que tampoco sea utilizable como excusa a la Administración para la adopción de tales medidas la inexistencia de créditos presupuestarios, pues la habilitación de los mismos no es condicionante para la existencia del derecho que se reconoce sino que, por el contrario, será una consecuencia de su declaración»"

Esta diferencia entre fuente jurídica del gasto público y fuente de las obligaciones del Estado que señalaba el Tribunal Constitucional, se asumió en la Ley 47/2003, de 26 de noviembre, General Presupuestaria, reconociendo en su exposición de motivos que «En cuanto a las obligaciones de la Hacienda Pública, la ley reitera la diferencia entre fuente jurídica del gasto público y fuente de las obligaciones del Estado, de modo que no basta con que la obligación nazca para que la misma le sea exigible a la Hacienda Pública, siendo preciso que resulten de la ejecución de los Presupuestos, de sentencia judicial firme o de operaciones no presupuestarias legalmente autorizadas, diferenciación que es una exigencia constitucional derivada del artículo 134.1 de la Carta magna, recogida por la doctrina del Tribunal Constitucional en su Sentencia número 63/1986, de 21 de mayo, reiterada en las Sentencias números 146/1986 y 13/1992». Y así se plasmó en el artículo 21.1 sobre exigibilidad de las obligaciones: "Las obligaciones de la Hacienda Pública estatal sólo son exigibles cuando resulten de la ejecución de los presupuestos, de conformidad con lo dispuesto en esta Ley, de sentencia judicial firme o de operaciones no presupuestarias legalmente autorizadas».

Todo ello tiene como consecuencia que la apreciación de un vicio de nulidad en la actuación administrativa no conlleva juicio alguno sobre la existencia o inexistencia de una obligación o deuda de la Administración frente tercero, pues ésta puede haber nacido de cualquiera de las fuentes de las obligaciones que señala el Ordenamiento jurídico. Cuando el art. 20 LGP nos dice que la obligaciones de la Hacienda Pública nacen de la ley, de los negocios jurídicos y de los «actos o hechos que la generen»-, se está dando entrada a figuras como el cuasi-contrato o la prohibición del 
enriquecimiento injusto, que son capaces de generar un título jurídico hábil para reclamar el cumplimiento de las obligaciones a la Hacienda, con independencia de que el negocio o acto no tenga todos los requisitos administrativos o presupuestarios necesarios para su validez. La falta de consignación presupuestaria erigida en causa de invalidez administrativa del acto, contrato o subvención no sería por lo tanto, un obstáculo para el reconocimiento de las obligaciones de la Hacienda frente a terceros.

\section{SOBRE LA APLICACIÓN DEL PROGEDIMIENTO DE RE- CONOCIMIENTO EXTRAJUDICIAL DE GRÉDITOS}

En esta doble realidad interna y externa de los gastos realizados sin consignación presupuestaria, hemos visto la solución que adoptan los Jueces y Tribunales cuando media reclamación en vía jurisdiccional por parte del deudor, consolidándose una Jurisprudencia que aplica la doctrina del enriquecimiento injusto en orden al reconocimiento de la obligación. A su vez estas sentencias de reconocimiento dictadas generan una fuente de gasto en el sentido del art. 21.1. LGP, completándose así la coherencia del sistema.

Ello no obstante, dentro del ámbito presupuestario, la propia legislación hacendística prevé otro procedimiento extraordinario que posibilita dar una solución al problema planteado por la adquisición de compromisos de gastos sin consignación presupuestaria, cual es el denominado procedimiento de reconocimiento extrajudicial de crédito, contemplado en el art. 34.3 LGP, pero también en los artículos 42 del TRLGHPJA y 176 del TRLRHHLL. Conforme a dicho art. 34.3 LGP: «3. Podrán aplicarse a créditos del ejercicio corriente obligaciones contraídas en ejercicios anteriores, de conformidad con el ordenamiento jurídico, para las que se anulara crédito en el ejercicio de procedencia. Asimismo, podrán atenderse con cargo a créditos del presupuesto del ejercicio corriente obligaciones pendientes de ejercicios anteriores, en los casos en que figure dotado un crédito específico destinado a dar cobertura a dichas obligaciones, con independencia de la existencia de saldo de crédito anulado en el ejercicio de procedencia».

En el caso de la legislación andaluza, y en idéntico sentido el art. 176 TRLRHHLL", es el artículo 42 TRLGHPA bajo el título "Temporalidad de los créditos", el que señala el camino a seguir en estos casos:

6 "Artículo 176. Temporalidad de los créditos.

1. Con cargo a los créditos del estado de gastos de cada presupuesto sólo podrán contraerse obligaciones derivadas de 
"1. Con cargo a los créditos del estado de gastos consignados en el Presupuesto, solamente podrán contraerse obligaciones derivadas de gastos que se realicen en el año natural del ejercicio presupuestario.

2. No obstante, se aplicarán a los créditos del Presupuesto vigente, en el momento de expedición de las órdenes de pago, las obligaciones siguientes:

a) Las que resulten de la liquidación de atrasos a favor del personal al servicio de la Comunidad Autónoma.

b) Las derivadas de compromisos de gasto debidamente adquiridos en ejercicios anteriores.

La Consejería competente en materia de Hacienda determinará, a iniciativa de la Consejería correspondiente, los créditos a los que habrá de imputarse el pago de estas obligaciones."

Se arbitra así un procedimiento presupuestario específico, que excepcionando el principio general de temporalidad de los créditos mediante el reconocimiento extrajudicial de los mismos, permite asumir compromisos de gastos correspondientes a ejercicios anteriores o al ejercicio en curso que no fueron tramitados por falta de consignación presupuestaria, o que derivan de actuaciones irregulares diversas ${ }^{7}$. Con ello la Administración puede hacer efectivos pagos a que un tercero tiene derecho, evi-

adquisiciones, obras, servicios y demás prestaciones o gastos en general que se realicen en el año natural del propio ejercicio presupuestario.

2. No obstante lo dispuesto en el apartado anterior, se aplicarán a los créditos del presupuesto vigente, en el momento de su reconocimiento, las obligaciones siguientes:

a) Las que resulten de la liquidación de atrasos a favor del personal que perciba sus retribuciones con cargo a los presupuestos generales de la entidad local.

b) Las derivadas de compromisos de gastos debidamente adquiridos en ejercicios anteriores, previa incorporación de los créditos en el supuesto establecido en el artículo 182.3."

${ }^{7}$ Por lo demás, desde el punto de vista contable es una exigencia del art $159.1 \mathrm{~g}$ ) de la LGP, adoptar las medidas oportunas para incorporar información sobre estos gastos realizados sin consignación presupuestaria. Ello a su vez, deriva del necesario cumplimiento de lo dispuesto en la L.O. 2/2012, de Estabilidad Presupuestaria y Sostenibilidad Financiera, que incluye como uno de sus principios generales el de transparencia, señalando que la contabilidad de las Administraciones Publicas y del resto de los sujetos comprendidos en el ámbito de aplicación de la Ley, deberá contener información suficiente y adecuada que permita verificar su situación financiera, el cumplimiento de los objetivos de estabilidad presupuestaria y sostenibilidad financiera y a observancia de los requerimientos acordados en la normativa europea sobre la materia. En este sentido, la modificación operada por la Ley de Presupuestos Generales del Estado para 2012 en la LGP introduciendo este apartado g) en el artículo 159.1 tenía como objetivo posibilitar la realización de las actuaciones necesarias para detectar la posible existencia de obligaciones derivadas de gastos realizados o bienes y servicios recibidos para los que no se hubiera producido su imputación contable o no hubieran sido cuantificados adecuadamente (Acuerdo 4/2013, de 27 de junio del Consejo de Política Fiscal y Financiera sobre la adopción de medidas normativas por parte de las Comunidades Autónomas necesarias para incorporar la obligación de que los órganos de control interno de la gestión económico financiera realicen anualmente actuaciones de control en la entidades no sometidas normativamente a auditoría de cuentas, que permitan verificar la existencia de obligaciones derivadas de gastos realizados o bienes y servicios recibidos para los que no se ha producido su consignación presupuestaria). 
tando el enriquecimiento injusto de la Administración, y dando satisfacción a las obligaciones contraídas por la Hacienda pública. En este sentido, el fundamento material de este procedimiento presupuestario, es el mismo que el de los procedimientos administrativo y judicial, pues como señala el Tribunal de Cuentas en el Informe de fiscalización sobre los gastos ejecutados por las entidades locales sin crédito presupuestario de 23 de diciembre de 2013: «La necesidad de establecer un procedimiento especial para la imputación de las obligaciones contraídas sin crédito presupuestario se motiva por la obligación que tiene la Administración de imputar todos los gastos a presupuesto y abonarlos, en aplicación de la teoría general de las obligaciones del derecho civil (art. 1089) y de la reiterada jurisprudencia del Tribunal Supremo que impide el enriquecimiento injusto" (pag. 9).

Lo interesante en este caso, es que el seguimiento de este procedimiento presupuestario -que presupone la tramitación del oportuno expediente ${ }^{8}$-, tiene a su vez incidencia en el ámbito interno o administrativo.

Ya habíamos visto que la sanción prevista por el Ordenamiento jurídico para estos pagos sin consignación en el Presupuesto es la nulidad de pleno derecho de los actos dictados, así como de las disposiciones con rango inferior a Ley. Sin embargo, cuando se sigue un procedimiento presupuestario de reconocimiento extrajudicial de créditos, se opera una cierta transformación de dichos actos o disposiciones nulas, y aunque no puede hablarse propiamente de convalidación del acto nulo, -por cuanto por definición éste no es convalidable (STS 21-3-1991)-, es lo cierto que la actuación administrativa realizada primigeniamente sin consignación presupuestaria y por tanto nula, se consolida en el sistema jurídico. Podríamos así decir que ha operado una especie de «sanación» del acto calificado como nulo por

${ }^{8}$ Para PRADA RODRÍGUEZ y HERRERO GONZÁLEZ, es necesario tramitar expediente a efecto, en forma tal que practicadas las oportunas diligencias previas, será preciso elaborar memoria o informe en el que se haga constar expresión de las causas por las que no se procedió a la imputación presupuestaria en el ejercicio de procedencia, motivando la necesidad de tramitar el expediente y evitar el enriquecimiento injusto; fecha o periodo de realización de los gastos, así como una relación de las facturas debidamente conformadas por los responsables de los servicios correspondientes; acreditación de que la imputación de los gastos no causará perjuicio ni limitación alguna para la realización de las atenciones del ejercicio corriente aportando el correspondiente certificado de existencia de crédito en las correspondientes partidas presupuestaras en las que hayan de imputarse los gestos según su naturaleza, y, en el supuesto de inexistencia o insuficiencia del mismo, orden de incoación del oportuno expediente de modificación de crédito; confección de la liquidación del contrato o de la indemnización que se ha de aprobar; recepción formal de la obra o servicio así como la aprobación de proyecto en caso de obras, ya que con posterioridad a la ejecución ha de aprobarse el proyecto correspondiente con el suficiente alcance que permita que las obras queden perfectamente definidas y, en consecuencia, delimitado el dominio público. Revista AUDITORIA PÚBLICA, nº 66 (2015) pag. 123. 
el legislador, al margen de las posibilidades que ofrece el art. 52 de la Ley 39/2015, de 1 de octubre de Procedimiento Administrativo Común de las Administraciones Públicas (LPC), que sólo permite la convalidación de los actos anulables, pero no de aquellos para los que la Ley impone la sanción de nulidad radical.

Si hemos de decir que sobre este particular, la doctrina administrativista ya había criticado la exclusión de los supuestos de nulidad radical de la técnica de la subsanación. BELADIEZ ROJO ${ }^{9}$ ha puesto de manifiesto acertadamente, que esta exclusión carece de sentido, desde el momento en que «para determinar si procede o no esta técnica de convalidación lo que hay que tener en cuenta es si el defecto puede ser corregido, siendo irrelevante la calificación jurídica que se otorgue a la invalidez del acto». Y ello lo demuestra estudiando los argumentos que tradicionalmente se emplean para justificar la prohibición de subsanar los actos nulos: su falta de efectos y la relevancia del vicio cometido. Respecto de la regla quod nullum est nullum efectum producit, afirma que sencillamente no es cierta, pues como puso de manifiesto SANTAMARÍA PASTOR ${ }^{10}$ «todo acto físicamente posible avalado por una voluntad de ejecución posee eficacia en tanto no es privado de ella por un pronunciamiento judicial», lo que siendo válido para cualquier acto jurídico, aun lo es más para los actos administrativos, dada la presunción de validez que adorna a todos ellos. Tampoco es convincente para la autora el argumento de la gravedad del vicio cometido, dada la especifica naturaleza de esta técnica convalidatoria, que elimina precisamente el vicio determinante de la invalidez, con lo que el grave defecto de que adolecía desaparece, conservándose en todo un acto acorde con la legalidad.

En esta misma línea CHINCHILLA MARTÍN ${ }^{11}$, se pregunta por el sentido que pueda tener impedir a la Administración subsanar los defectos más graves, sobre todo teniendo en cuenta que la técnica de la subsanación podría encontrar su asiento precisamente en la obligación de la Administración de ajustarse al principio de le-

${ }^{9}$ BELADIEZ ROJO, M., "Validez y eficacia de los actos administrativos", Editorial Marcial Pons, 1994, pag. 243.

${ }^{10}$ SANTAMARÍA PASTOR, J., "La nulidad de pleno derecho de los actos administrativos", IEA,

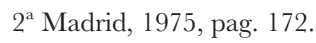

${ }^{11}$ CHINCHILLA MARTín, C., "Nulidad y anulabilidad", pag. 212, en "La nueva Ley de Régimen Jurídico de las Administraciones Públicas y del Procedimiento Administrativo Común", Dir. LEGUINA VILLA, J., y SANCHEZ MORÓN, M., Tecnos, 1993. 
galidad. Al respecto, BOQUERA OLIVER ${ }^{12}$ nos recuerda que la prohibición de convalidación de los actos nulos, «no es una consecuencia lógica de la infracción gravísima del Ordenamiento jurídico, sino querida e impuesta por el legislador». También la admite BACA ONETO ${ }^{13}$, aun reconociendo que tendrá carácter excepcional. Y es cierto que en determinados casos, los vicios del acto nulo serán insubsanables porque la propia naturaleza jurídica del vicio lo impide ${ }^{14}$. Pero puede asumirse siguiendo en este punto a BELADIEZ ROJO ${ }^{15}$ que «si la corrección del defecto implica una modificación del contenido del acto administrativo, la eliminación del vicio conllevará la anulación del acto o al menos de una parte del mismo, ya que toda modificación de un acto administrativo supone dictar un acto administrativo distinto del que se dictó, lo que con carácter general sólo se puede lograr con la anulación; por el contrario, si el defecto se corrige sin afectar al contenido del acto, al haber corregido el vicio sin tener que anular ninguna parte del mismo, éste se habrá convalidado». La afectación o no del contenido, es pues lo que ha de determinar las posibilidades subsanatorias del acto incurso en causa de nulidad plena, siendo así que en el caso presente, la falta de consignación presupuestaria es una circunstancia exterior que adorna al contenido de acto administrativo, pero que no penetra en su esencia, de ahí que subsanado el defecto por la vía de la actuación del procedimiento administrativo de reconocimiento extrajudicial de créditos, dotando de consignación en el presupuesto el gasto efectuado, el acto queda implícitamente sanado, pues el vicio determinante de su nulidad ha sido corregido.

Podríamos así decir, que estamos ante un supuesto especial en el que la tesis de la teoría clásica sobre la nulidad de los actos administrativos ${ }^{16}$-defensora de su radical ineficacia por la asimilación a la categoría de acto inexistente-, decae, por cuanto la ficción en la que se asienta para defender la inhabilidad o incapacidad de producir efectos de los actos nulos ab initio, choca frontalmente con el hecho de que el presupuesto que permite poner en marcha el procedimiento de reconocimiento ex-

12 BOQUERA OLIVER, J.M., "Derecho Administrativo”, Cívitas, 1996, pag. 375.

13 BACA ONETO, V.S., "La invalidez de los contratos administrativos". Thomson-civitas, 2006, pag. 83 .

${ }^{14}$ CHINCHILLA MARTÍN, cita como ejemplos de vicios de imposible convalidación el caso de los actos administrativos que sean constitutivo de un delito o falta, o tengan un contenido imposible. Ibidem, pag. 212.

15 Ibidem, pag. 201.

${ }^{16}$ Representada entre otros por GARGíA LUENGO, J., "La nulidad de pleno derecho de los actos administrativos", Cívitas, 2002, y BOCANEGRA SIERRA, R., "Lecciones sobre el acto administrativo", Thomsom/Civitas, 2006. 
trajudicial de créditos es precisamente la previa existencia de un acto que adolece de un grave vicio constitutivo de nulidad que es preciso subsanar (la falta de consignación presupuestaria), con lo que implícitamente se está reconociendo que existe un acto administrativo sobre el que actuar la subsanación.

Y es que como señala REBOLLO PUIG ${ }^{17}$, mantener «en toda su pureza la teoría clásica de la nulidad y su ineficacia total haría que no se explicara bien la realidad jurídica española», pues aun cuando esta aplicación exacta de las teorías civilistas al acto administrativo puede deslumbrar por su claridad, la asimilación del acto nulo a acto jurídicamente inexistente «hace que la carencia total efectos se imponga a cualquier otra consideración, ya sea la seguridad jurídica, la protección de la buena fé o los plazos de los recursos». SANCHEZ MORÓN ${ }^{18}$ por su parte nos recuerda que las diferencias entre el Derecho privado y el Derecho Administrativo «son importantes y se fundan en la posición institucional que la Administración tiene como gestora de los intereses públicos y en las prerrogativas que la Ley le otorga para el cumplimiento de sus fines. De donde se deriva un régimen peculiar de la invalidez de los actos administrativos, que no sólo es propio de nuestro Derecho, sino también en líneas generales, común a otros ordenamientos europeos y al Derecho de la Unión Europea». Otros autores llegan incluso a ir más allá relativizando absolutamente los efectos de la nulidad de pleno derecho. Así NIETO GARCíA ${ }^{19}$, llega a afirmar que «La distinción entre efectos ex tunc y efectos ex nunc es un mito del que hay que desprenderse cuanto antes de la misma manera que ya nadie cree, desde hace mucho tiempo, en el otro mito de que los actos nulos no pueden producir efectos: si esto fuera cierto, no habría necesidad de impugnar los actos viciados de nulidad. El Derecho Administrativo y las prerrogativas de la Administración han pulverizado los conceptos de nulidad y anulabilidad, de los que sólo se conservan pedazos rotos que los autores se empeñan en reconstruir para volver a darles una forma primitiva que ya es imposible».

17 REBOLLO PUIG, M., "La nulidad en Derecho administrativo (Consideración de su significado y régimen en el actual Derecho Administrativo español a propósito de la nulidad de los derechos fundamentales). Justicia administrativa: Revista de derecho administrativo. ISSN 1139-4951, Nº. 44, 2009, págs. 5-39.

18 SÁNCHEZ MORÓN, M., "Derecho administrativo. Parte General”. Tecnos, 2014, pags. 564 y 565 .

${ }^{19}$ NIETO GARCÍA, A., en el Estudio preliminar del libro de BELADIEZ ROJO, M., "Validez y eficacia de los actos administrativos", Editorial Marcial Pons, 1994, pag. 17 
Pero entre las posturas maximalistas que identifican al acto nulo con el acto inexistente, y aquellas otras que asimilan los efectos de los actos nulos y anulables, probablemente sea más adecuado seguir las tesis intermedias que propugnan la necesidad de modular los efectos de los actos nulos. Postulados maximalistas como los defendidos por la doctrina clásica a lo que llevan es a interpretar las normas en forma contraria a lo mandatado por el legislador, desde el momento en que se prescinde del resto del Ordenamiento jurídico, y se llega a interpretaciones literalistas que aíslan al precepto del propio esquema normativo en el que se inserta. Pero al tiempo relativizar la diferencia entre lo nulo y lo anulable supone también supone ignorar la voluntad del Legislador, que ha querido imputar consecuencias distintas en atención a los diferentes vicios en que puedan incurrir los actos administrativos.

Como con toda razón señala REBOLLO $\mathrm{PUIG}^{20}$, no nos queda sino admitir «que el régimen de la nulidad no es del todo homogéneo, que sus consecuencias no se producen siempre en bloque y con la máxima intensidad que reclamaba la teoría clásica al asimilarla a la inexistencia ni con la mínima que llega casi a identificarla con la anulabilidad, sino que se pueden moldear según la concreta ilegalidad en que incurra el acto nulo, los intereses en juego y la confrontación con otras reglas y principios». Y este es precisamente el quid de la cuestión: los principios y valores esenciales del Ordenamiento jurídico no pueden ser desconocidos, sino que deben integrarse en cualquier aplicación dogmática de la teoría de las nulidades administrativas. El principio constitucional de seguridad jurídica (art. 9.3 CE), el de buena fe, confianza legítima o la prohibición de enriquecimiento injusto, deben ser útiles para «moderar» aplicaciones dogmáticas de la nulidad de pleno derecho. Y es que un concreto mandato jurídico (nulidad del acto) sólo puede considerarse correctamente ejecutado, cuando se puede realizar sin vulnerar otros intereses superiores que también sean merecedores de tutela jurídica por parte del Legislador. En este caso, nuestro Legislador, al arbitrar un procedimiento presupuestario específico que permite subsanar el vicio de falta de consignación presupuestaria, ha considerado necesario modular los efectos de su previa declaración de nulidad de pleno derecho del acto, en pos de la protección de valores superiores de nuestro ordenamiento jurídico, tales como la seguridad jurídica, la confianza legítima de los terceros y la prohibición de enriquecimiento injusto de la Administración.

Pero no sólo se trata de que los efectos de la nulidad en este caso puedan modularse actuando el específico procedimiento presupuestario de reconocimiento ex-

${ }^{20}$ Ibidem. Pag. 39. 
trajudicial de créditos, sino que al tiempo, también la propia configuración legislativa del procedimiento administrativo general de revisión de oficio de los actos nulos previsto en el art. 106 de la Ley 39/2015, de 1 de octubre de Procedimiento Administrativo Común de las Administraciones Públicas (LPC)-, permite dicha modulación. Y es que si el acto administrativo incurso en causa de nulidad por falta de consignación presupuestaria consigue dotarse de la misma por actuación de los mecanismos de derecho presupuestario, es claro ya no va a ser razonable ni posible iniciar el procedimiento de revisión de oficio, por expreso mandato del legislador, que expresamente excluye la posibilidad de su inicio «cuando por prescripción de acciones, por el tiempo transcurrido o por otras circunstancias, su ejercicio resulte contrario a la equidad, a la buena fe, al derecho de los particulares o a las leyes», según el art. 110 de la nueva LPC. Iniciar un procedimiento de revisión de oficio respecto de una actuación por falta de consignación presupuestaria cuando ya cuenta con ella por obra del procedimiento presupuestario de reconocimiento extrajudicial, afecta directamente al derecho de los particulares y resulta claramente contrario a la equidad, con lo que en ningún caso procedería su inicio.

La importancia capital de este precepto (anterior art. 106 LRJPAC), ya había sido resaltada por REBOLLO PUIG ${ }^{21}$, poniendo el acento en que la propia existencia de este precepto «Es una prueba irrefutable de que el acto nulo de pleno derecho no es un acto que, por sus caracteres intrínsecos, no pueda producir efectos, de que la nulidad no se impone natural e irremisiblemente a cualquier otro principio o valor. Ante este artículo, no puede dejar de reconocer que la nulidad se domestica, y el dogma de su ineficacia absoluta cae. Se podrá decir que el articulo 106 LAP ha de administrarse con enorme prudencia. No importa. Su misma existencia es suficiente para probar la relativización de la nulidad y de la omnipotente fuerza expansiva de su ineficacia»

Estamos por lo tanto, ante un caso muy especial dentro de la categoría de los actos nulos, para el que el Ordenamiento jurídico, -si bien no prevé expresamente su convalidación-, si su consolidación en la vida administrativa, primando la presunción de validez del acto administrativo. En cualquier caso debe hacerse notar que este procedimiento presupuestario de reconocimiento extrajudicial presupone un juicio previo sobre el título obligacional, desde el momento en que es condición indispensable para la aplicación de los créditos del Presupuesto vigente a los gastos contraídos en ejercicios anteriores, que estos sean «debidos», esto es, que se trate de «gastos

21 Ibidem, pag. 33. 
debidamente adquiridos», lo que nos sitúa en la órbita del art. 103.1 de la Constitución, en cuanto la Administración Pública debe servir siempre «los intereses generales», en forma tal, que si se comprueba que la actuación administrativa no se acompasa a este principio general, la aportación de consignación presupuestaria ya no procederá en vía de procedimiento administrativo. Otra cosa será que la Administración pudiera ser condenada al pago en vía judicial para evitar su enriquecimiento injusto $^{22}$, o que ello tenga posteriores consecuencias en los gestores en materia de responsabilidad, cuestión ésta que analizaremos a continuación.

\section{RESPONSABILIDAD}

Hasta el momento presente, hemos descrito las consecuencias que los gastos sin consignación presupuestaria y pendientes de realización tienen tanto desde la perspectiva del procedimiento administrativo como frente a su exigibilidad por terceros. Existen no obstante, otras consecuencias jurídicas internas derivadas de este tipo de actuaciones ajenas al mandato de los artículos 46 LGP, 39.2 TRLGHPA y 176.5 TRLRHHLL, pues las tres normas hacendísticas después de afirmar la existencia de causa de nulidad en la actuación administrativa, añaden como coletilla final que todo ello lo es "sin perjuicio de las responsabilidades a que haya lugar".

Estas responsabilidades a que se refieren los preceptos citados, son las propias de la responsabilidad contable administrativa que contienen los artículos 176 y siguientes de la LGP y 108 y siguientes del TRLGHPA, y en concreto los artículos 177 c) LGP, y en similares términos, el 109 c) del TRLGHPA, pero también -y esta es la novedad-, a las responsabilidades por «Infracciones en materia de gestión económico-presupuestaria», que ahora dimanan de los artículos 28 y siguientes de la Ley 19/2013, de 9 de diciembre, de transparencia, acceso a la información pública y buen gobierno.

Comenzando por el ámbito de la responsabilidad contable, es el art. 176 c) LGP, el que considera como hecho que puede generar responsabilidad «c) Comprometer gastos, liquidar obligaciones y ordenar pagos sin crédito suficiente para realizarlos o con in-

\footnotetext{
22 Sobre la actuación de nuestros Tribunales en la materia, resultan sumamente interesantes los artículos de REBOLLO PUIG "Enriquecimiento injusto y nemo auditor en el Derecho Administrativo" Cuadernos de derecho local, ISSN 1696-0955, Número 12, 2006, págs. 7-37; y "Nemo auditur propriam turpitudinem allegans" en la jurisprudencia contencionso-administrativa". Documentación administrativa, ISSN 0012-4494, No 263-264, 2003 (Ejemplar dedicado a: El Principio de seguridad jurídica y sus manifestaciones), págs. 185-221.
} 
fracción de lo dispuesto en esta ley o en la de Presupuestos que sea aplicable». Este tipo de responsabilidad contable administrativa - que debe cumplir todos los requisitos materiales que al efecto se exigen para la responsabilidad jurisdiccional contable que se actúa ante el Tribunal de Cuentas ${ }^{23}$-, se hace efectiva a través del procedimiento previsto en el Real Decreto 700/1988, de 1 de julio, por el que se regulan los expedientes administrativos de responsabilidad contable, todo ello conforme a la remisión que al efecto realiza el art. 20.2 del Reglamento de los procedimientos en materia de responsabilidad patrimonial aprobado por el R.D. 429/1993, de 26 de marzo. En el caso de la Comunidad Autónoma de Andalucía el art. 109 c) del TRLGHPA incluye idéntica previsión, siendo así que no contando con regulación de procedimiento específico, la exigencia de responsabilidad también habrá de tramitarse por dicho procedimiento estatal por vía de supletoriedad (art. 149.3 CE).

Si queremos resaltar que esta responsabilidad es exigible con carácter general a todas las autoridades y personal al servicio de las Administraciones Públicas, pero que con carácter particular lo es a los interventores y ordenadores de pagos por imperativo de lo dispuesto en los artículos 179 LGP y 188 TRLRHHLL, al señalar que «En las condiciones fijadas en los artículos anteriores, están sujetos a la obligación de indemnizar a la Hacienda Pública estatal o, en su caso, a la respectiva entidad, además de los que adopten la resolución o realicen el acto determinante de aquélla, los interventores en el ejercicio de la función interventora, respecto a los extremos a los que se extiende la misma, y los ordenadores de pago que no ha-

${ }^{23}$ Debe recordarse que la tramitación procedimental de la responsabilidad contable depende de cuáles sean indiciariamente los hechos constitutivos de la posible infracción de las leyes reguladoras del régimen presupuestario, económico-financiero, de contabilidad y de control aplicables, distinguiéndose entre los supuestos previstos en las letras a (alcance y malversación) y el resto de los supuestos del art. 177 LGP, en forma tal que en el caso del alcance y malversación la responsabilidad debe ser exigida ante el Tribunal de Cuentas de conformidad con su legislación específica y en el resto de los supuestos a través de procedimiento administrativo tramitado al efecto conforme a lo previsto en la propia LGP. En el caso del TRLHPJA, los supuestos previstos en las letras a) y e) del art. 109 (alcance, malversación y no rendición de cuentas), se seguirán igualmente ante el Tribunal de Cuentas, en tanto que el resto se seguirá su exigencia a través de procedimiento administrativo previsto en el propio Texto Refundido. En cualquiera de los casos, como señala SALA SÁNCHEZ, tratamos en el caso de la responsabilidad contable administrativa de un tipo de responsabilidad que "supone la obligación de indemnizar a la Hacienda Pública de los daños y perjuicios causados a la misma”, con unos «requisitos configuradores que, en definitiva, son comunes con las mismas exigencias de la Ley orgánica del Tribunal de Cuentas y de su Ley de funcionamiento", en su artículo "La responsabilidad contable en la nueva Ley general presupuestaria". Revista Galega de Economía, vol. 16, núm. extraord. (2007). Por lo tanto, deben cumplirse todos los requisitos exigidos jurisprudencialmente para el reconocimiento la responsabilidad contable, esto es, que la actuación del empleado público o autoridad contraria a las normas de la Hacienda se haya realizado con «dolo o culpa graves» y haya ocasionado un efectivo menoscabo al erario público, dado que se trata de una responsabilidad de tipo resarcitorio. 
yan salvado su actuación en el respectivo expediente, mediante observación escrita acerca de la improcedencia o ilegalidad del acto o resolución». Por su parte la norma autonómica fija dicha responsabilidad en forma genérica en el artículo 108.1, pero sin referencia expresa a los funcionarios de la intervención. Eso sí, en el art.110.2 impone a la Intervención el deber legal de poner en conocimiento del gestor administrativo la posible existencia de responsabilidad contable.

Pero como antes decíamos, tras la publicación de la Ley 19/2013, de transparencia, acceso a la información pública y buen gobierno, la exigencia de responsabilidad contable de las normas hacendística y presupuestaria se entrecruza con un nuevo régimen de infracciones y sanciones en materia de gestión económico-presupuestaria, que además conlleva anexa responsabilidad.

Conforme a lo que dispone el art. 28 de la señalada norma, constituye infracción muy grave haber incurrido en «c) Los compromisos de gastos, reconocimiento de obligaciones y ordenación de pagos sin crédito suficiente para realizarlos o con infracción de lo dispuesto en la Ley 47/2003, de 26 de noviembre, General Presupuestaria, o en la de Presupuestos u otra normativa presupuestaria que sea aplicable». Como puede comprobarse, el supuesto fáctico es idéntico al contemplado en el art. 177 c) LGP. A más: no sólo este supuesto es idéntico sino que también lo son los contemplados en las letras a), b) y e), respecto del art. 177, letras a), b) y e) del artículo de la LGP.

Las penas previstas para esta infracción muy grave, se contemplan en el artículo 30.2, 3 y 4, debiendo imponerse «en todo caso» las siguientes:

a) La declaración del incumplimiento y su publicación en el «Boletín Oficial del Estado» o diario oficial que corresponda.

b) La no percepción, en el caso de que la llevara aparejada, de la correspondiente indemnización para el caso de cese en el cargo

c) la destitución del cargo que ocupen salvo que ya hubieran cesado y la imposibilidad de ser nombrados para ocupar ningún puesto de alto cargo o asimilado durante un periodo de entre cinco y diez años.

A ello se suma la previsión del artículo 30.8 de la Ley 13/2013, por cuanto suma al régimen sancionador la obligación de restitución, dado que «En todo caso la comisión de las infracciones previstas en el artículo 28 conllevará las siguientes consecuencias:

a) La obligación de restituir, en su caso, las cantidades percibidas o satisfechas indebidamente. 
b) La obligación de indemnizar a la Hacienda Pública en los términos del artículo 176 de la Ley 47/2003, de 26 de noviembre, General Presupuestaria».

Vista la regulación, observamos dos problemas en el caso de comisión de esta infracción muy grave. De un lado, la comisión de la infracción administrativa que nos ocupa tiene un carácter marcadamente objetivo, siendo así que donde se permite su modulación es en la aplicación de las sanciones conforme a los criterios de ponderación que recoge el art. 30.5 de la norma. Estos criterios son los de la naturaleza y entidad de la infracción, gravedad del peligro ocasionado o del perjuicio causado, ganancias obtenidas, consecuencias desfavorables de los hechos para la Hacienda Pública, o haber procedido a la subsanación de la infracción por propia iniciativa y reparación de los daños o perjuicios causados, a lo que debe sumarse conforme al principio de proporcionalidad y por expresa remisión a lo previsto en el art. 131.3 de la LRJPAC ${ }^{24}$, la valoración de la intencionalidad o reiteración, naturaleza de los perjuicios causados y reincidencia. Ocurre sin embargo, que tanto el apartado 3 como el apartado 4, son absolutamente imperativos cuando señalan las penas que corresponden a este tipo de infracciones muy graves, pues nos dice que se impondrán «en todo caso», y que los sancionados «serán» destituidos, con lo que poco margen queda para la ponderación. Cuestión distinta hubiera sido que se permitiera la graduación de la infracción en atención a las circunstancias, pudiendo calificarse en su caso simplemente como grave o leve, o que por el tipo de pena previsto pudiera graduarse la intensidad del hecho infractor como ocurre por ejemplo cuando la pena es una multa. Hay aquí por lo tanto, una cierta incongruencia normativa que sin duda puede ocasionar problemas al operador del Derecho, pues difícil será ante la rigidez del sistema de penas aplicar el principio de proporcionalidad, lo que las más de las veces llamará a dejar a tales infracciones sin castigo, con la indeseada consecuencia como señala el Tribunal de Cuentas, de que «La falta de exigibilidad de responsabilidades incentiva el incumplimiento del procedimiento de ejecución del gasto público, mediante la ejecución de gastos sin crédito presupuestario» ${ }^{25}$.

De otro vemos como la norma prevé que el régimen sancionador se acompañe de medidas reparadoras del daño causado. Pero la sede propia de exigencia de estas medidas es el ámbito de la responsabilidad contable. Así, el art. 30.8 nos dice que

\footnotetext{
${ }^{24}$ Ahora, nuevo art. 29 de la Ley 40/2015, de 1 de octubre de Régimen jurídico del Sector Público.

25 Informe de 23 de diciembre de 2013, de Fiscalización sobre los gastos ejecutados por las entidades locales sin crédito presupuestario, pag. 41.
} 
además de las sanciones, la comisión de tales infracciones previstas en el art. 28 tiene como consecuencia «en todo caso», la de imponer la obligación de restituir las cantidades percibidas o satisfechas indebidamente «en su caso», así como la obligación de indemnizar a la Hacienda Pública en los términos del artículo 176 de la Ley 47/2003, de 26 de noviembre, General Presupuestaria, esto es, nos reconduce de forma directa al ámbito propio de la responsabilidad contable administrativa. Por lo tanto la Ley de transparencia, acceso a la información pública y buen gobierno, anuda a la comisión de una infracción en materia de gestión económico-presupuestaria, la obligación de restitución e indemnización a la Hacienda Pública de modo necesario («en todo caso», se dice). Pero a continuación, el mismo precepto es consciente de que desde la perspectiva contable existen una serie de exigencias que es preciso cumplir en orden a que la misma pueda ser apreciada, de ahí que incluya que la obligación de restituir, lo será "en su caso". Y es que como antes señalábamos, los requisitos que se requieren para apreciar este tipo de responsabilidad contable son idénticos en el procedimiento administrativo y en el jurisdiccional, en cuanto que en ambos casos se exige no sólo la causación del daño y nexo de causalidad, sino además el elemento subjetivo del dolo o culpa, situándonos en un ámbito de responsabilidad distinta de la administrativa, al tener naturaleza eminentemente resarcitoria. Por lo tanto, y aun cuando el artículo 30.8 sea tan tajante al utilizar la expresión "en todo caso" pareciendo así que la responsabilidad resarcitoria es una consecuencia que se sigue de modo necesario a la comisión de una infracción, es lo cierto que tal responsabilidad podrá darse o no, pues si no se cumplen todos los elementos precisos para la apreciación de este tipo de responsabilidad, no habrá obligación de restitución o indemnización alguna.

Por lo tanto, lo que impone la norma imperativamente a la Administración es la obligación de iniciar al tiempo y paralelamente al procedimiento sancionador, otro procedimiento administrativo en orden a decidir sobre la posible responsabilidad resarcitoria que pudiera corresponder a los sujetos infractores. Esto es, no se trata de que en sede de procedimiento sancionador se proceda a la apertura de pieza separada capaz de dilucidar la responsabilidad del sujeto infractor partiendo de una misma valoración de los hechos, sino que de lo que se trata es de que proceda a la tramitación de dos procedimientos administrativos paralelos, a partir de los mismos presupuestos fácticos, que en consecuencia exigirán valoración diferenciada, lo que evidentemente, puede generar problemas. Así el artículo 31.1 de la Ley de transparencia, acceso a la información pública y buen gobierno, nos dice que «La responsabilidad será exigida en procedimiento administrativo instruido al efecto sin perjuicio de dar conocimiento de los hechos al Tribunal de Cuentas por si procediese, en su caso, la incoación del oportuno procedimiento de responsabilidad contable». Ello se completa con lo que dispone el art. 30.7, cuando señala que respecto de este tipo de infracciones en mate- 
ria de gestión económico-presupuestaria se podrá tramitar «el procedimiento de responsabilidad patrimonial simultáneamente al procedimiento sancionador». Por lo tanto, es nítido que el legislador está remitiendo el conocimiento de la posible responsabilidad a un procedimiento distinto del sancionador, cual es el previsto en el artículo 176 de la LGP, por remisión expresa del artículo 30.8 de la Ley.

Por otro lado, no se entiende muy bien esa distinción que contiene el artículo 30.8 de la Ley 19/2013, entre «obligación de restituir» y «obligación de indemnizar en los términos del artículo 176 de la Ley 47/2003, de 26 de noviembre, General Presupuestaria», pues como antes hemos señalado, la responsabilidad contable que recoge el artículo 176 LGP es justamente resarcitoria. O como dice el Tribunal Supremo, se trata de una «una subespecie de la responsabilidad civil, en que pueden incurrir quienes tengan a su cargo el manejo de caudales o efectos públicos, consistente en la obligación de indemnizar los daños y perjuicios causados» (STS 27-10-2011).

Puede por tanto decirse que en esta materia la Ley 19/2013, adolece de una cierta imprecisión, lo que puede afectar a la coherencia del sistema.

\section{CONGLUSIONES}

Los créditos consignados en los estados de gastos de los Presupuestos constituyen autorizaciones y limitaciones de gasto al poder ejecutivo. Y aun cuando el ámbito propio de su incidencia es el interno, en forma tal que las previsiones contenidas en las Leyes de Presupuestos condicionan y conforman la actuación administrativa, no puede obviarse la incidencia que estas autorizaciones presuponen para terceros proveedores de la Administración.

En este sentido, la existencia de crédito presupuestario, es requisito de validez de la actuación administrativa que genera la realización del gasto público, en forma tal que en el caso de que se comprometan gastos sin consignación presupuestaria, la actuación administrativa estará incursa en causa de nulidad de pleno derecho. Sin embargo, externamente en relación con los terceros, los Presupuestos no son título jurídico ni constitutivo ni impeditivo para el válido nacimiento de obligaciones económicas para las Administraciones Públicas. La existencia o no de consignación presupuestaria es indiferente a estos efectos. Las obligaciones de la Hacienda Pública nacen de la Ley, de los negocios jurídicos, así como de «los actos o hechos que, según Derecho, las generen», y por lo tanto, la exigibilidad de las obligaciones por parte de terceros, depende de la existencia de un título jurídico hábil a estos efectos, no de la validez de la actuación administrativa. 
Para solucionar esta desconexión entre exigibilidad de la obligación y necesario cumplimiento de la legalidad material, con el imperativo de la legalidad presupuestaria, nuestro Ordenamiento jurídico - al margen de la reclamación ante los Tribunales de Justicia-, ofrece a la Administración Pública la posibilidad de reconocimiento de las obligaciones a través del procedimiento presupuestario específico de reconocimiento extrajudicial de créditos, dotando de consignación presupuestaria al acto o contrato que hasta el momento estaba privado de ella, y que por ello devenía nulo de pleno derecho. Se salva o subsana así un vicio de invalidez administrativa actuando el procedimiento especial presupuestario, y al tiempo, se imposibilita el inicio del procedimiento administrativo general de revisión de oficio para anular el acto incurso en causa de nulidad de pleno derecho, lo que suscita el interesante debate de si por esta vía se está operando la convalidación de los actos nulos, en contra de la regla general fijada en el art. 52 de la Ley 39/2015, de 1 de octubre de Procedimiento Administrativo Común de las Administraciones Públicas. A su vez, esa posibilidad de subsanación, nos obliga a interrogarnos sobre si verdaderamente es posible seguir manteniendo los postulados de la doctrina clásica en cuanto a los efectos que cabe reconocer a la nulidad de pleno derecho de los actos administrativos.

Entendemos en este punto con la mejor doctrina administrativista, que no cabe mantener en la materia postulados maximalistas, que a la postre hunden sus raíces en el Derecho civil, pero que no tienen presente ni las peculiaridades del Derecho Público teñido por la defensa del interés público, ni los principios y valores esenciales que el Ordenamiento jurídico también protege y que es preciso salvaguardar, y en consecuencia procede defender la posibilidad de modulación de los efectos de la nulidad de pleno derecho en supuestos como el presente, en que la falta de concordancia entre la realidad material y la presupuestaria no puede ser argumento para el incumplimiento de otros importantes principios generales tales como la confianza legítima, la seguridad jurídica o la prohibición de enriquecimiento injusto.

Otras consecuencias jurídicas que se derivan de la adquisición de compromisos de gastos sin consignación presupuestaria son la posible existencia de responsabilidad contable, o la imposición de sanciones en materia de buen gobierno a las autoridades o empleados públicos responsables, lo que a su vez, lleva aparejado el inicio de un procedimiento de responsabilidad contable para el resarcimiento de los gastos o daños generados a la Administración. Esta vía, y no la de la declaración tajante de nulidad de pleno derecho de las actuaciones administrativas, es la que debe ser explorada en orden a conseguir el efectivo y adecuado cumplimiento de los procedimientos de ejecución presupuestaria por ser la más eficaz en orden a alcanzar este fin, buscando la adecuada coherencia interna de la norma de transparencia en relación además con los presupuestos de la responsabilidad contable. 


\section{BIBLIOGRAFIÍA}

BACA ONETO, VÍCTOR SEBASTIÁN (2006): La invalidez de los contratos administrativos. Thomson-civitas.

BELADIEZ ROJO, MARGARITA (1994): Validez y eficacia de los actos administrativos. Editorial Marcial Pons.

BOCANEGRA SIERRA, RAÚL (2006): Lecciones sobre el acto administrativo. Thomsom/Civitas.

BOQUERA OLIVER, JOSÉ MARÍA (1996): Derecho Administrativo, Cívitas.

CHINCHILLA MARTÍN, CARMEN (1993): “Nulidad y anulabilidad” en la obra colectiva: La nueva Ley de Régimen Jurídico de las Administraciones Públicas y del Procedimiento Administrativo Común, Dir. LEGUINA VILLA, J., y SÁNCHEZ MORÓN, M., Tecnos.

FERREIRO LAPATZA, JOSÉ JUAN (2006): Curso de Derecho Financiero español. Marcial Pons.

GARCÍA LUENGO, JAVIER (2002): La nulidad de pleno derecho de los actos administrativos. Cívitas.

MENÉNDEZ MORENO, ALEJANDRO (2013): "Efectos jurídicos de las Leyes de Presupuestos Generales del Estado". Lex Nova Thomson Reuters. 2013.

NIETO GARCÍA, ALEJANDRO (1994): "Estudio preliminar" del libro de BELADIEZ ROJO, M.: Validez y eficacia de los actos administrativos. Editorial Marcial Pons.

SALA SÁNCHEZ, PASCUAL., "La responsabilidad contable en la nueva Ley general presupuestaria” en Revista Galega de Economía, vol. 16, núm. extraord. (2007).

PRADA RODRÍGUEZ, ALBA y HERRERO GONZÁLEZ, ELENA (2015): “Reconocimiento extrajudicial de crédito", en Revista AUDITORÍA PÚBLICA, nº 66.

PITA GRANDAL, ANA MARÍA y FERNÁNDEZ LÓPEZ, ROBERTO IGNACIO (2007): "El procedimiento de ejecución del gasto público ante situaciones de emergencia". Revista Española de Derecho Financiero num. 133/2007.

REBOLLO PUIG, MANUEL (2009): "La nulidad en Derecho administrativo (Consideración de su significado y régimen en el actual Derecho Administrativo español a propósito de la nulidad de los derechos fundamentales)" en Justicia administrativa: Revista de derecho administrativo. ISSN 1139-4951, $\mathrm{N}^{\circ} .44$.

REBOLLO PUIG, MANUEL (2006): "Enriquecimiento injusto y nemo auditor en el Derecho Administrativo" en Cuadernos de derecho local, ISSN 1696-0955, Número 12.

REBOLLO PUIG, MANUEL (2003): "Nemo auditur propriam turpitudinem allegans en la jurisprudencia contencioso-administrativa" en Documentación administrativa, ISSN 0012-4494, No 263-264 (Ejemplar dedicado a: El Principio de seguridad jurídica y sus manifestaciones). 
SALA SÁNCHEZ, PASCUAL (2007): "La responsabilidad contable en la nueva Ley General Presupuestaria" en Revista Galega de Economía, vol. 16.

SÁNCHEZ MORÓN, MIGUEL (2014): Derecho administrativo. Parte General. Tecnos.

SANTAMARÍA PASTOR, JUNA ALFONSO, "La nulidad de pleno derecho de los actos administrativos", IEA, 2a Madrid, 1975, pag. 172. 